\title{
CORNEAL NEOVASCULARISATION IN ACUTE HYDROPS
}

\author{
NEIL J. ROWSON, JOHN K. G. DART and ROGER J. BUCKLEY \\ London
}

\begin{abstract}
SUMMARY
Four cases of corneal neovascularisation complicating acute hydrops in keratoconus are presented. Three cases were atopic. In two cases high doses of topical steroids failed to inhibit the neovascular process.

The pathogenesis of neovascularisation in this situation is uncertain. Risk factors may be the size of the hydrops and the proximity of oedematous cornea to the limbal vascular arcades, with an associated inflammatory reaction. The coexistance of atopic keratoconjunctivitis may be an additional factor.

Patients with large peripheral hydrops should be observed closely for the development of new vessels, and systemic steroids prescribed if topical medication fails to inhibit a neovascular reaction. Consideration should be given to the possibility of removing the stimulus to neovascularisation by corneal grafting, although the technical difficulties and the patients atopic state may militate against this.
\end{abstract}

The management of acute hydrops corneae in keratoconus is expectant. The condition is self-limiting ${ }^{1}$ and the scarring that results is seldom axial and can cause flattening of the cornea with an improvement in contact lens fit and visual acuity. ${ }^{2,3}$ If keratoplasty is indicated for visual reasons it is technically easier, and therefore safer, after the hydrops has resolved. ${ }^{4}$

The prognosis for patients undergoing penetrating keratoplasty for uncomplicated keratoconus is usually good, however, we have recently seen four patients whose acute hydrops was complicated by the development of corneal new vessels, and who now carry an increased risk of graft rejection because of this. ${ }^{5,6}$ To our knowledge this complication has not been described before.

\section{CASE REPORTS}

\section{Case 1.}

A 17 year old male presented with eczema and mild atopic keratoconjunctivitis. Keratoconus had been diagnosed at the age of 11 years.

Correspondence to: Neil J. Rowson F.C.Ophth., Moorfields Eye Hospital, City Road, London EC1V 2PD, England.
His visual acuities were right eye $6 / 6$, left eye $6 / 9$ wearing hard contact lenses until he developed acute hydrops in the left eye. He was prescribed cycloplegic drops and advised to continue using his previous treatment of sodium cromoglycate $2 \%$ drops.

He was seen at two-weekly intervals and a month after onset the hydrops had enlarged to involve nearly the whole of the inferior cornea. Deep new vessels were seen to extend $0.5 \mathrm{~mm}$ from the inferior limbus (Fig. 1). He was prescribed guttae dexamethasone $0.1 \%$ four times daily, increasing to eight times daily without apparent effect on the neovascularisation which eventually extended to $4 \mathrm{~mm}$ from the limbus (Figs. $2 \& 3$ ). The hydrops finally resolved ten weeks after its onset and his acuity stabilised at left eye 6/24 unaided, 6/9 with a contact lens.

\section{Case 2.}

A 15 year old girl presented who suffers from severe atopic eczema and atopic keratoconjunctivitis. Keratoconus was diagnosed when she was 13 years old when her acuities were right eye $6 / 9$ unaided, and left eye $2 / 36$ with a contact lens.

Two years later the right cornea became hydropic. At first the oedema was confined to the centre of the cornea but a week later it had extended to the limbus inferiorly.

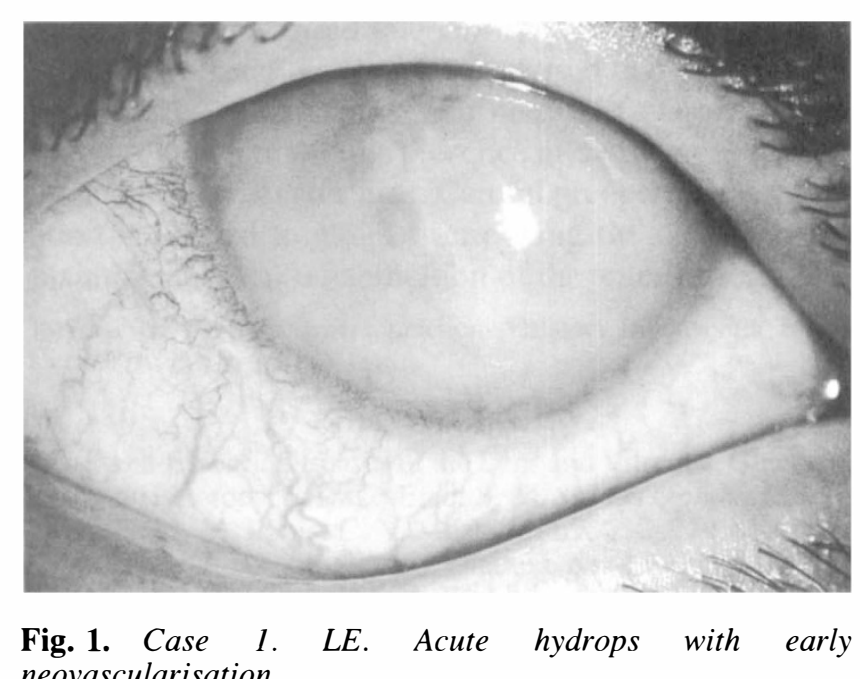

neovascularisation. 


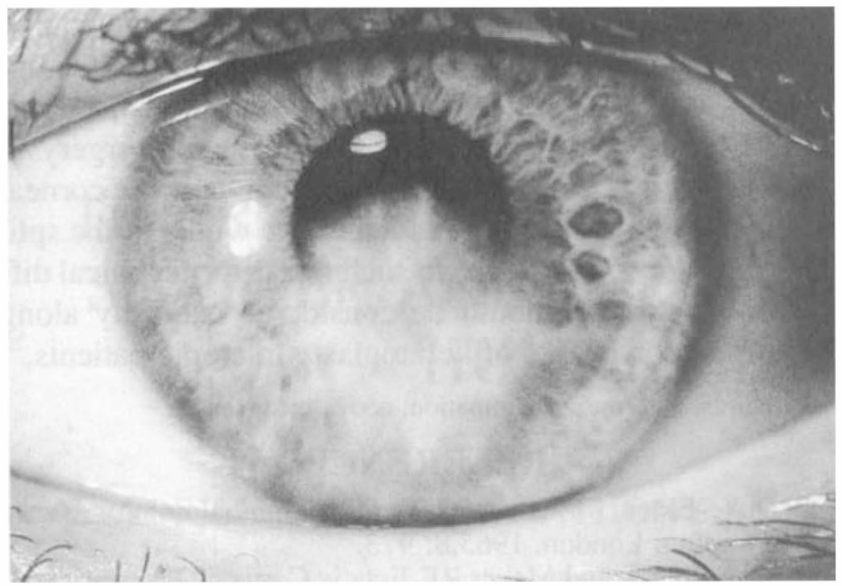

Fig. 2. Case 1. LE. Resolved hydrops with stromal scarring and $4 \mathrm{~mm}$ new vessels.

She was already on guttae prednisolone $0.1 \%$ once daily for her allergic eye disease and the dose was not increased at this time. Four weeks later deep new vessels were noted inferiorly. Her treatment was changed to guttae prednisolone $0.3 \%$ four times daily and continued until her hydrops resolved leaving vessels extending $3 \mathrm{~mm}$ into the cornea (Fig. 4). At her most recent visit to the clinic the acuity of the right eye was $6 / 60$ and N10, with a scleral contact lens.

\section{Case 3.}

A 23 year old, non-atopic female. Keratoconus was diagnosed at the age of 15 years. Her visual acuities were right eye $6 / 18$, left eye $6 / 12$ with contact lenses, when she developed acute hydrops of the right cornea. This was treated initially with topical antibiotics. She did not reattend for two months when the cornea was still grossly oedematous with deep new vessels extending $4 \mathrm{~mm}$ from the limbus (Fig. 5). Guttae dexamethasone $0.1 \%$ six times a day was prescribed, with betamethasone ointment at night. This treatment was maintained for a month.

The hydrops resolved in six months (Fig. 6) and her acuity is now $6 / 36$.

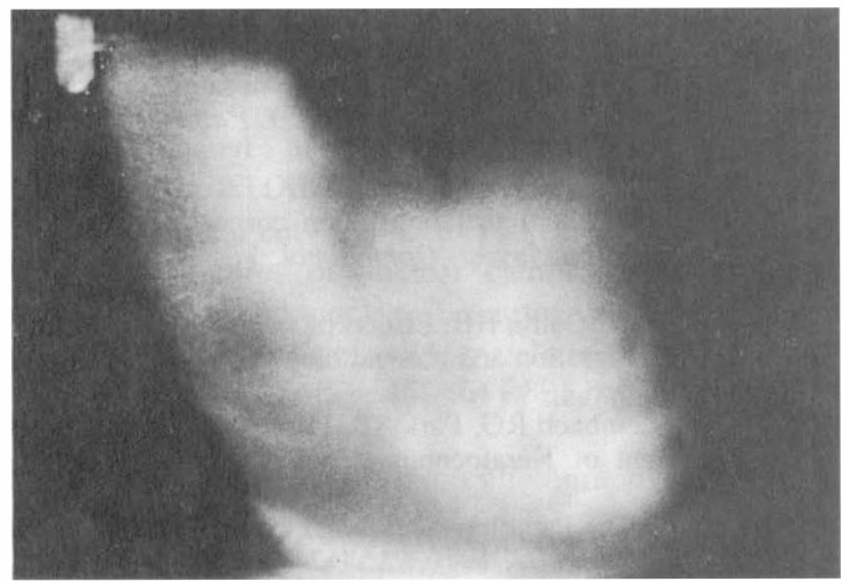

Fig. 3. Case 1. LE. High power view of resolved hydrops and new vessels.

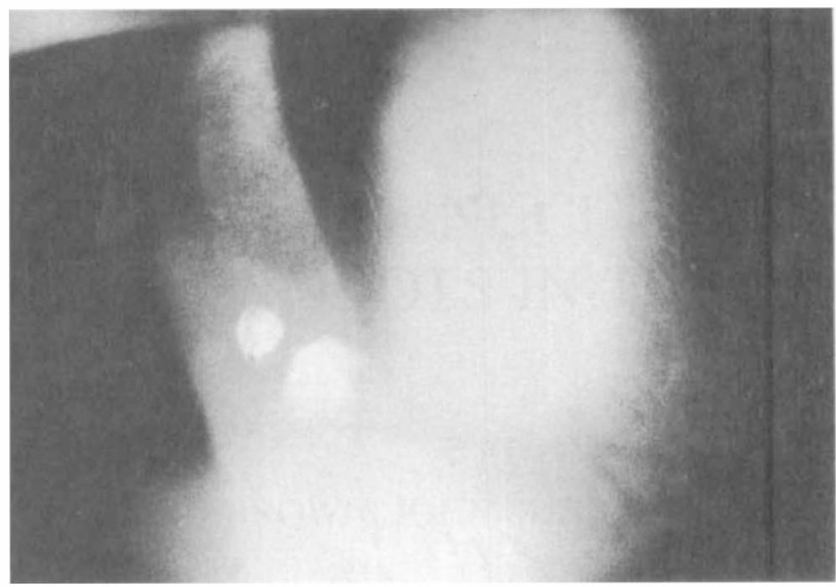

Fig. 4. Case 2. RE. Corneal new vessels in resolved hydrops.

Case 4.

A 26 year old, mildly atopic man. Keratoconus was diagnosed at the age of eight years. Deep new vessels extend to the visual axis in his left eye following acute hydrops some years before. No details were available on the treatment he had received.

\section{DISCUSSION}

Neovascularisation is a feature of many corneal disorders but is not a recognised risk in acute hydrops corneae which usually resolves spontaneously and may result in visual improvement in some cases. Conventional management of hydrops is directed towards the relief of symptoms and the prevention of infection in the acute phase.

In the 1940s Cogan ${ }^{7}$ reported that while experimental lesions in the peripheral cornea vascularise, central ones do not, and he drew attention to the association between oedema and neovascularisation. Subsequent work has shown, however, that oedema alone is not a sufficient stimulus to neovascularisation; ${ }^{8}$ it is seldom seen in cases of Fuchs' endothelial dystrophy. Fromer and Klintworth have demonstrated that neovascularisation is usually preceded by leukocytic infiltration and that the neovascular response is inhibited in animals rendered leukopaenic by

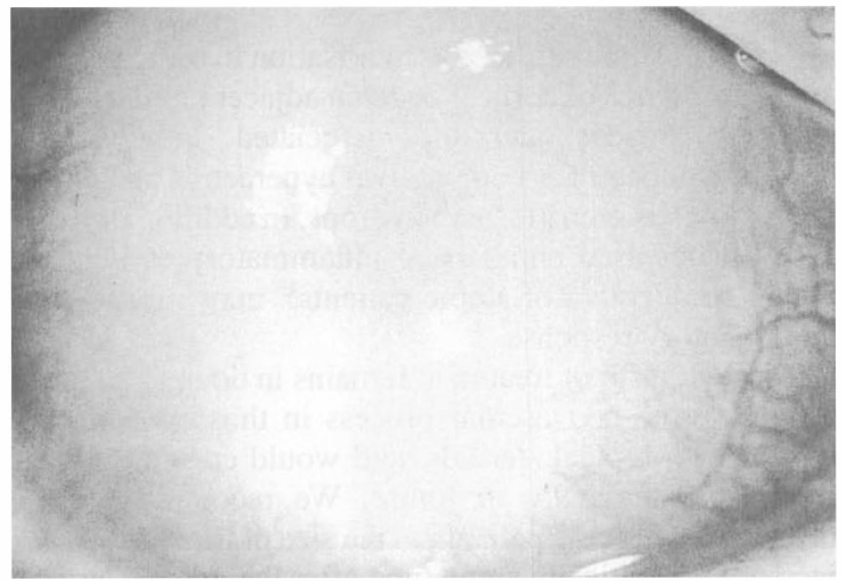

Fig. 5. Case 3. RE. Acute hydrops with stromal neovascularisation. 


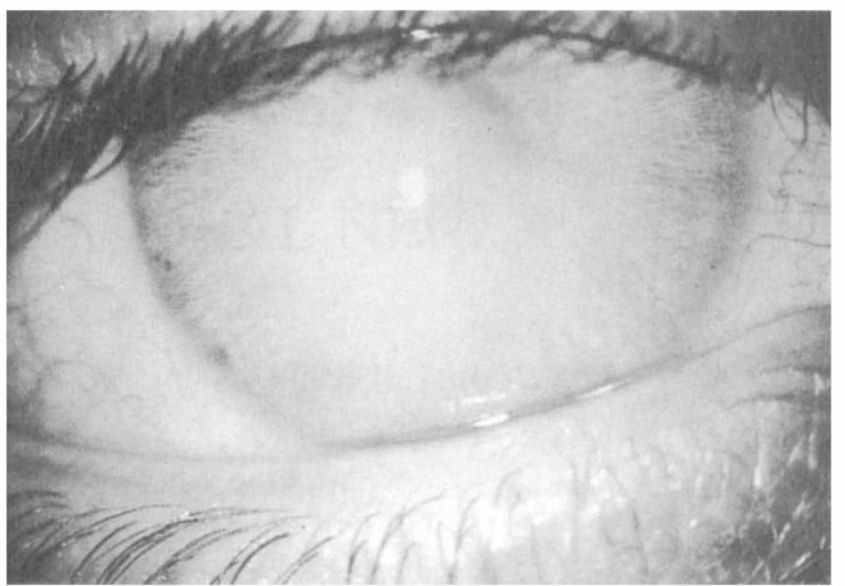

Fig. 6. Case 3. RE. Resolved hydrops with new vessels.

bone marrow irradiation; ${ }^{9,10,11}$ except in embryonic tissues and tumours there has yet to be a convincing demonstration of neovascularisation occurring in the absence of inflammation. ${ }^{12}$ The existance of a diffusable vasoproliferative substance was postulated by Campbell and Michaelson in $1949^{13}$ and prostaglandins of the E series, histamine and interleukin 1 have been implicated as well as various polypeptides associated with the healing phase of the inflammatory response: somatomedins and tissue growth factors. ${ }^{12}$ Both the cellular and the vascular responses have been inhibited in animals by topical steroids. $^{10,15,16,17}$

Corneal neovascularisation in acute hydrops is a rare phenomenon, but one which has a significant bearing on the patient's future management and prognosis.

On the basis of our clinical experience we suggest that the size of the hydrops, and particularly its proximity to the limbus, are major risk factors. The role of atopy is difficult to assess, but it is our clinical impression that the most severe keratoconus occurs in young atopes. The incidence of acute hydrops may therefore be higher in this group of patients.

Lass and co-workers studied 417 patients with keratoconus and found a mean age at diagnosis of 28 years. ${ }^{18}$ The relative youth of our patients may be significant as they were all diagnosed much younger than this (mean 12 years).

Potential stimuli to neovascularisation in acute hydrops are the presence of corneal oedema adjacent to the limbal vascular arcades and the associated inflammatory response, apparent as conjunctival hyperaemia and ciliary flush, which is seen in severe hydrops. In addition the presence of increased numbers of inflammatory cells in the bulbar conjunctiva of atopic patients ${ }^{19}$ may enhance this inflammatory response.

The best form of treatment remains in doubt. We failed to control the neovascular process in those patients we treated with topical steroids, and would consider giving steroids systemically in future. We recommend close observation of these patients as the size of the hydrops can increase dramatically some time after the onset (Case 1). In our cases neovascularisation began two to four weeks after the onset of hydrops.
We hesitate to recommend early corneal transplantation in these patients because of the possibility of a satisfactory natural outcome, with a successful return to contact lens wear. Theoretically there may be a case for surgery in severe hydrops if new vessels begin to invade the corneal stroma, providing a graft ca include the whole of the split in Descemet's membrane. In such a case the technical difficulties involved should be considered carefully along with the known risks of keratoplasty in atopic patients. ${ }^{20}$

Key words: Hydrops; inflammation; neovascularisation.

\section{REFERENCES}

1. Duke-Elder, Sir Stuart. System of Ophthalmology. Henry Kimpton, London. 1965,8: 973.

2. Maguire LJ, and Meyer RF. Ectatic Corneal Degenerations. In Kaufman HE, Barron BA, McDonald MB and Waltman SR (eds): The Cornea. Churchill Livingstone, New York 1988, 485-510.

3. Doughman DJ: Corneal Edema. In Duane TD: Clinical Ophthalmology. JB Lipincott Company, Philadelphia 1988, 4: 16A:11.

4. Shaw EL: Pathophysiology and Treatment of Corneal Hydrops. Ophthalmic Surg. 1976, 7: 33.

5. Duke-Elder, Sir Stuart. System of Ophthalmology. Henry Kimpton, London 1965,8: 657.

6. Rycroft BW: Corneal Grafts. Butterworth, London 1955, 249.

7. Cogan DG: Vascularisation of the Cornea. Its experimental induction by small lesions and a new theory of its pathogenesis. Arch. Ophthalmol. 1949, 41: 406-16.

8. Maurice DM, Zauberman H. and Michaelson IC: The Stimulus to Neovascularisation of the Cornea. Exp. Eye Res. 1966, 5: 168-84.

9. Fromer $\mathrm{CH}$ and Klintworth GK: An Evaluation of the Role of Leukocytes in the Pathogenesis of Experimentally Induced Corneal Vascularisation I. Am. J. Pathol. 1975, 79: 537-54.

10. Fromer $\mathrm{CH}$ and Klintworth GK: An Evaluation of the Role of Leukocytes in the Pathogenesis of Experimentally Induced Corneal Vascularisation II. Am. J. Pathol 1975, 81: $531-44$.

11. Fromer $\mathrm{CH}$ and Klintworth GK: An Evaluation of the Role of Leukocytes in the Pathogenesis of Experimentally Induced Cornéal Vascularisation III. Am.J. Pathol 1976, 82: 157-70.

12. Klintworth GK: Corneal Angiogenesis. A Comprehensive Critical Review. Springer-Verlag, New York, 1990, 23-50.

13. Campbell FW and Michaelson IC: Blood Vessel Formation in the Cornea. Br. J. Ophthalmol 1949, 33: 248-55.

14. Parke A, Bhattacherjee P, Palmer RM, Lazarus NR: Characterisation and quantification of copper sulfate-induced vascularisation of the rabbit cornea. Am. J. Pathol 1988, 130: 173.

15. Haynes WL, Proia AD, Klintworth GK: Effect of inhibitors of arachidonic acid metabolism on corneal neovascularisation in the rat. Invest. Ophthalmol. Vis. Sci. 1989, 30: 1588.

16. Hoban BP and Collin HB: Effects of salicate and steroid on neutrophil migration and corneal blood vessel growth. Am. J. Physiol. Opt. 1986, 63: 271.

17. Lass JH. Lembach RG, Park SB, Hom DL, et al. Clinical Management of Keratoconus. Ophthalmology 1990, 96: 433-45.

18. Morgan G: The Pathology Of Vernal Conjunctivitis. Trans. Ophthalmol. Soc. UK 1971, 91: 467-78.

19. Lyons CJ, Dart JKG, Aclimandos WA, Lightman S, Buckley RJ: Sclerokeratitis after Keratoplasty in Atopy. Ophthalmology1990, 97: 729-33. 